\title{
Pelatihan Literasi Media Digital dan Keamanan Data untuk Pelajar SMA Islam Al Fajar
}

\author{
Titin Setiawati ${ }^{1}$,Nurlina Rahman ${ }^{2}$, dan Vilya Dwi Agustini ${ }^{3}$ \\ 1,2,3 Universitas Muhammadiyah Prof. Dr. Hamka, Jakarta, Indonesia
}

\begin{abstract}
ABSTRAK
Sejak pandemi Covid-19, kalangan Pelajar semakin aktif menggunakan internet karena proses kegiatan mengajar banyak dialihkan ke media internet. Bahaya mengincar anak-anak remaja yang berinternet tanpa panduan dan dilandasi kesadaran bagaimana menggunakan internet yang bijak dan penyimpanan data yang aman. Pelatihan ini ditunjukan untuk memberikan kesadaran bagaimana menggunakan internet dengan bijak dan mampu melindungi data pribadi mereka dari bahaya scam dan phising yang kasusnya kian naik dari tahun ketahun. Pengabdian dilakukan secara offline dengan memperhatikan protokol kesehatan ketat. Feedback yang didapatkan cukup baik dengan kehadiran 60 siswa SMA Perguruan Al Fajar yang mengikuti pelatihan hingga selesai.
\end{abstract}

Kata Kunci: media internet, keamanan data, remaja

\begin{abstract}
Since the pandemic, students have become increasingly active in using the interne due to teaching activities has been diverted to the internet. Danger target teenagers who use the internet media without guidance and awareness of how to secure confidential data and use the internet wisely. This training is intended to provide awareness on how to use the internet wisely and be able to protect their personal data from the dangers of scams and phishing cases whose cases are increasing from year to year. The training is held offline with strict health protocols. The feedbacks that was obtained was quite good with the presence of 60 Al Fajar High School students who participated and accomplish the training.
\end{abstract}

Keywords: internet media, data security, youth

\section{PENDAHULUAN}

Keamanan berinternet merupakan masalah krusial hari ini. Perkembangan media internet yang begitu pesat, seringkali tidak diiringi oleh kesadaran masyarakat akan berbagai bahaya yang mengintai ketika berada di dunia maya. Masyarakat sering mengakses internet tanpa tahu konsekuensi apa saja yang bisa terjadi dengan apa yang dilakukannya. Aturan yang mengatur apa yang boleh dan tidak boleh dilakukan ketika menggunakan media internet belum dipahami, tetapi masyarakat sudah menjadikan media internet sebagai sumber 
informasi, media pergaulan, media rekreasi, media ekonomi dan lain sebagainya sehingga sering memunculkan berbagai masalah yang sebelumnya tidak terpikirkan.

Penyebaran berbagai data pribadi yang mudah terjadi sehingga sering menimbulkan masalah. Persoalan ini masih sering dianggap sebagai hal yang sederhana, padahal dalam kenyataannya, data pribadi yang tersebar dapat menimbulkan kerugian besar. Hanya lembaga tertentu yang memiliki kewenangan untuk mengumpulkan data pribadi. Kesadaran yang masih rendah mengenai keamanan data pribadi ini menimbulkan persoalan baru.

Kalangan remaja dan anak usia sekolah merupakan salah satu yang rentan dengan kejahatan internet. Sebagai kalangan yang sedang dalam fase peralihan dari anak-anak menuju dewasa, remaja sering mengalami berbagai gejolak dan menghadapi banyak pertanyaan tentang dirinya, sementara pengendalian diri belum maksimal. Faktor kehati-hatian belum begitu diperhatikan, ditambah lagi dengan ketidaktahuan tentang bahaya yang mengincar di media internet. Sementara penggunaan media internet saat ini sudah menjadi hal yang dilakukan setiap saat oleh siswa.

Perkembangan teknologi manusia sendiri menurut Marshal Mc Luhann dalam Technological Determinism (dalam Littlejohn, 1999) dibagi menjadi tribal age, literate age, print age, dan electronic age, dan saat ini berada dalam electronic age di mana komunikasi banyak dilakukan dengan menggunakan media elektronik. Perkembangan teknologi ini dapat mempengaruhi pola komunikasi manusia. Seperti dinyatakan oleh Nasrullah (2018) yang menyebutkan bahwa perkembangan media yang terjadi secara terus menerus turut mempengaruhi pola komunikasi dalam masyarakat. Media tersebut merupakan kepanjangan indera manusia. Karena meskipun manusia memiliki berbagai indera tetapi juga memiliki keterbatasan dalam menghayati lingkungan sekitarnya sehingga menciptakan teknologi sebagai alat bantu.

Salah satu hal dalam berinternet yang sering tidak disadari dan berkaitan dengan keamanan berinternet adalah soal realitas yang termediasi. Dalam dunia internet, realitas yang terjadi adalah realitas yang dikonstruksi dan dimediasi oleh teknologi, sehingga untuk orang tertentu yang tidak menyadari hal ini sering terjebak dengan persoalan baru karena menyangka bahwa realitas yang ada di dunia internet seperti halnya realita di dunia nyata. Seperti halnya yang diungkapkan oleh Wood \& Smith dalam bukunya Online Communication, Linking Technology, Identity \& Culture bahwa mediated communication even affects our perception of the world around us (Wood \& Smith, 2005:8). Wood \& Smith bahkan membagi identitas di media online dengan 3 kategori, yaitu reallife identity, pseudo-identity, dan new identity. Semua identitas tersebut dapat dikonstruksi dengan mudah di internet, dan dari sini terlihat bahwa dunia internet adalah dunia yang tidak sepenuhnya bisa dipercaya.

Penelitian (Setiawati \& Agustini, 2021) juga menemukan bahwa kalangan mahasiswa yang menggunakan media pembelajaran daring resmi dari kampus sekalipun sebanyak 0,3 persen 
tidak menggunakan identitas nama yang sebenarnya dan 54,3 persen tidak menggunakan foto yang sebenarnya. Hal ini kembali membuktikan bahwa identitas adalah masalah krusial, baik identitas yang tidak sebenarnya, maupun identitas pribadi yang seharusnya rahasia tetapi tersebar di media online.

Persepsi yang terbangun ketika menggunakan media, termasuk di dalamnya media daring yang pesat berkembang ini merupakan hasil dari representasi yang dikontsruksi oleh komunikator. Dan dalam media daring seseorang dapat menjadi komunikan maupun komunikator. Tanpa bekal pengetahuan yang cukup, seseorang sering menyebarkan data pribadi sehingga rentan menjadi korban kejahatan internet.

Termasuk di dalamnya adalah siswa SMA Perguruan Islam Al Fajar Bkeasi. Siswa SMA Perguruan Islam Al Fajar tidak menyadari bahaya yang dapat timbul dari penggunaan internet, sehingga penyebaran data pribadi masih sering terjadi yang dapat menimbulkan persoalan keamanan. Dibalik kemudahan dalam mengakses internet muncul masalah Cybercrimes yang merupakan perilaku illegal yang mengarah operasi elektronik yang target utama adalah data dalam sistem. Munculnya Cybercrimes ialah ketidaktahuan akan keamanan berinternet terutama tidak bisa membedakan situs yang benar-benar aman. (Seminar Nasional UNPAD, 2018). Sehingga kesadaran seorang pengguna dalam mengakses internet perlu disadari benar, karena sistem dengan mudah di hack tetapi kemampuan seorang dalam mengunakan internet dengan bijak yang perlu diberi perhatian.

Tujuan pelatihan ini adalah untuk memberikan pengetahuan dan kesadaran bagi SMA Perguruan Isman Al Fajar tentang pentingnya berinternet dengan aman. Dengan memberikan pelatihan aman berinternet yang komprehensif dan efektif, diharapkan siswa SMA Perguruan Islam Al Fajar, menjadi pengguna internet yang sadar akan keamanan dan bertanggung jawab dengan apa yang dilakukan ketika menggunakan media internet. Kegiatan ini melibatkan 60 siswa SMA Perguruan Islam Al Fajar yang merupakan perwakilan sekolah. Diharapkan dengan memberikan pelatihan kepada 60 siswa tersebut dapat memberikan pengetahuan tentang internet dan data pribadi yang aman dengan maksimal

\section{METODOLOGI PELAKSANAAN}

Metode Pelatihan yang digunakan dalam pengabdian ini berupa pemberian materi dan praktik langsung langkah-langkah melakukan setting sosial media untuk proteksi data pribadi. Adapun teknis pelaksanaan diberikan berupa: (1)pemberian materi, (2)praktik dan evaluasi. Setelah materi diberikan, dilanjutkan dengan praktik bagaimana melakukan setting privasi dan autentifikasi dua langkah di akun sosial media peserta pelatihan. Penyebaran post test dilakukan sebagai bahan evaluasi pelatihan. 
Adapun pelatihan dilakukan secara offline dengan jumlah peserta mencapai 60 siswa serta didampingi dengan dewan guru SMA Perguruan Islam Al Fajar Bekasi dengan tetap melakukan protokol kesehatan dengan menjaga jarak, melakukan screening suhu tubuh serta memakai masker

Gambar 1. Penjelasan tentang Keamanan Data Diri di Media Sosial



Sumber. Dokumentasi pribadi

Gambar 2. Praktik mensetting autentifikasi dua langkah sosial media

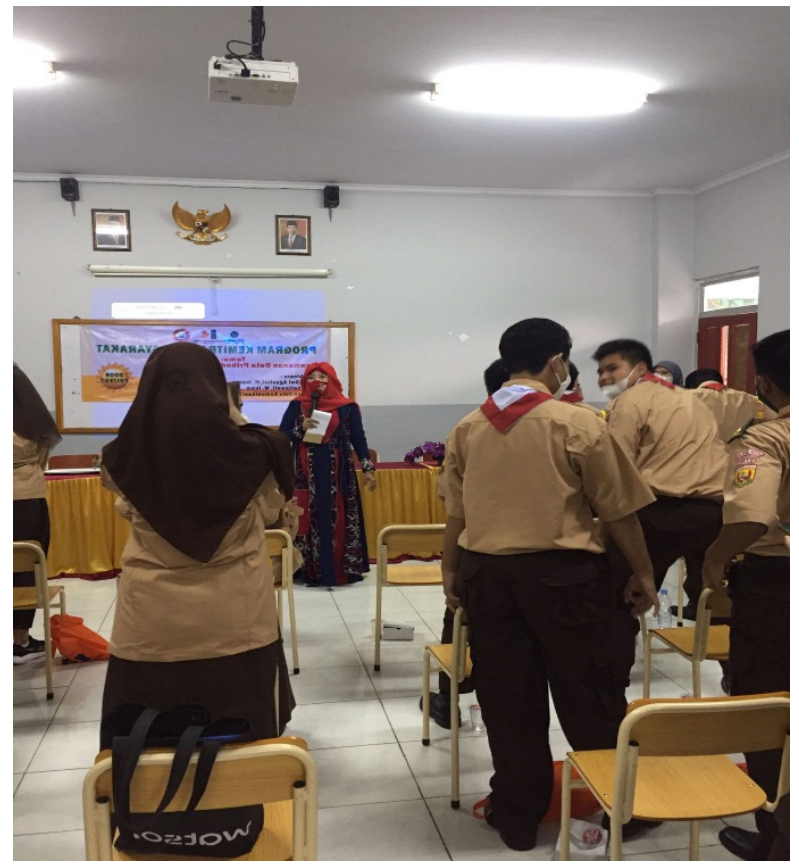

Sumber. Dokumentasi pribadi 


\section{HASIL DAN PEMBAHASAN}

Pelatihan ini dilaksanakan dengan latar belakang dari maraknya data pribadi yang sengaja atau tidak sengaja disebar di media sosial. Terlebih remaja sebagai pengguna sosial media aktif, kurang bahkan tidak mengetahui data pribadi apa yang seharusnya tidak di share ke publik. Sesuai dengan metode yang digunakan, maka pelatihan dimulai dengan pemberian materi dan pemahaman mengenai konsep apa itu data pribadi dan materi kedua serta praktik langsung antara penyuluh dan peserta, langkah-langkah melakukan setting, privasi di sosial media.

1. Data Pribadi

Apakah yang dimaksud dengan data pribadi. Dalam rancangan Undang-undang Perlindungan Data Pribadi (RUU PDP), data pribadi adalah setiap data tentang seseorang baik yang teridentifikasi secara tersendiri atau dikombinasi dengan informasi lainnya baik secara langsung maupun tidak langsung melalui sistem elektronik dan/atau nonelektronik. Sedangkan menurut UU Adminduk, ada beberapa data yang harus dilindungi antara lain;
a. Nomor KK (Kartu Keluarga)
b. NIK (Nomor Induk Kependudukan)
c. Tanggal/bulan/tahun lahir
d. Keterangan tentang kecatatan fisik dan/atau mental
e. NIK Ibu kandung
f. NIK ayah
g. Beberapa isi catatan peristiwa penting (ulang tahun, $\mathrm{dsb}$ )

2. Harus Dilindungi

Ada beberapa alasan data pribadi harus dilindungi
a. Menghindari intimidasi online
b. Mencegah penggunaan data pribadi oleh pihak tidak bertanggung jawab
c. Menghindari potensi pencemaran nama baik
d. Hak kendali atas data pribadi

3. UU ITE Yang Mengatur

Sebenarnya pemerintah dalam UU ITE dalam Pasal 26 ayat 3 sudah memberikan panduan bagi penyedia platform media sosial atau ecomers harus melakukan penghapusan data secara berkala dalam kurun waktu tertentu, tetapi pada praktiknya hal itu tidak terjadi. Dengan mengetahui potensi kerugian dari penyebaran data pribadi sebagai langkah preventif.

4. Pencurian Data

Pencurian data baik dilakukan dari pembajakan media sosial/ecomers tiap tahun mengalami kenaikan yang cukup memprihatinkan. 
Gambar 3. Grafik kasus pencurian data

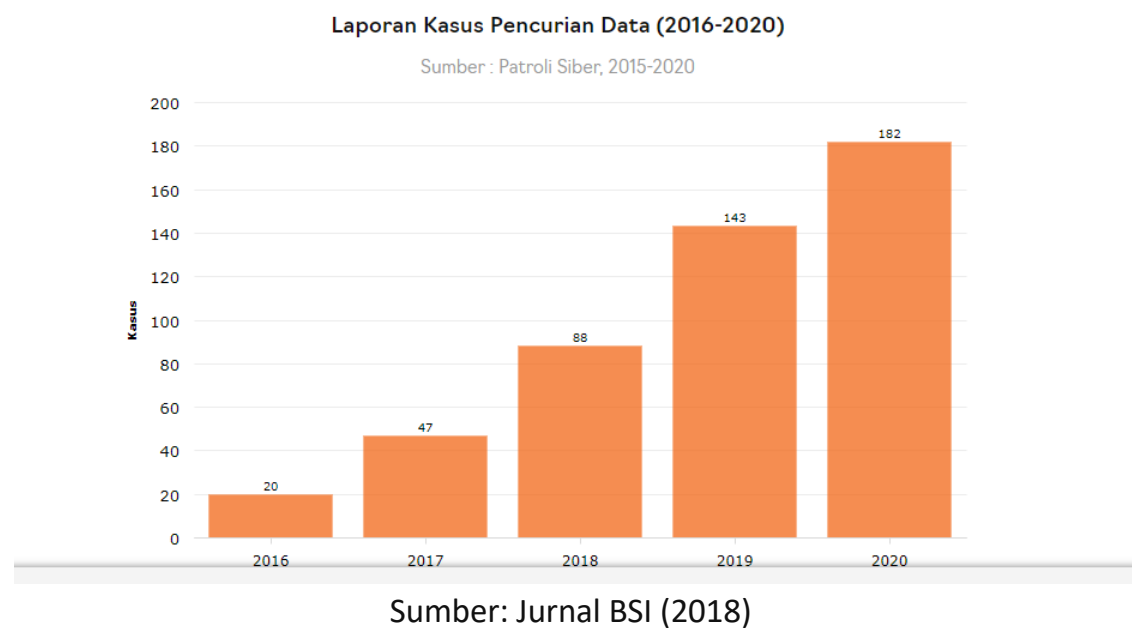

5. Security, Privacy dan setting FB, IG dan WA

Ada beberapa kekuatiran yang dialami pengguna sosial media antara lain takut accountnya kena Hack, Data dipakai pinjol, saldo ecomerc hilang dan sebagainya. Tetapi masih banyak yang belum tergerak melakukan langkah preventif seperti bagaimana melakukan security, privacy dan setting autentifikasi dua langkah yang sebenarnya sangat sederhana dan mudah untuk melindungi data pribadi. Berikut adalah panduan melakukan setting autentifkasi dua langkah FB, IG dan WA

\section{Gambar 4. Langkah setting FB}

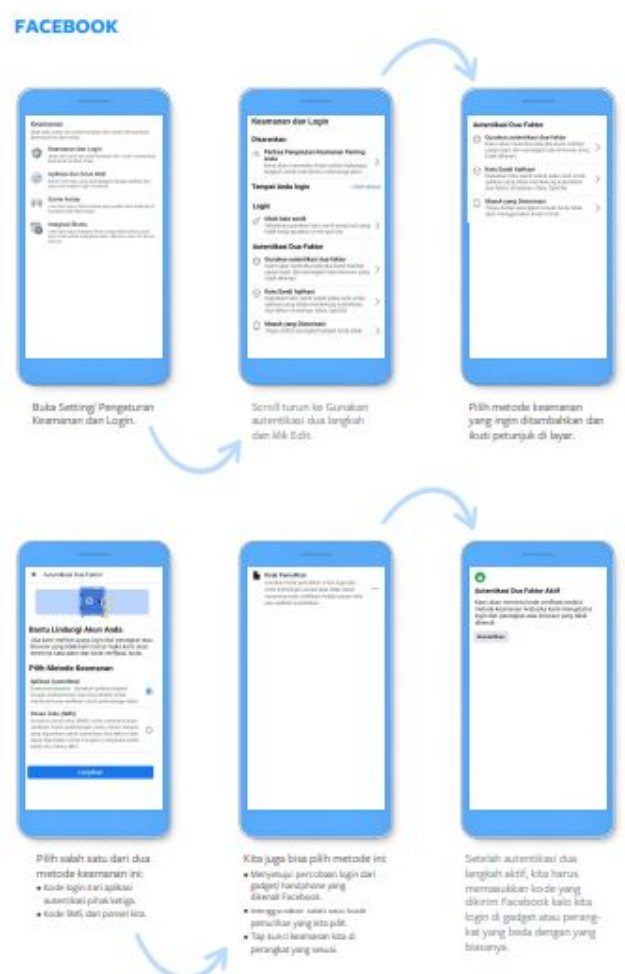

Sumber. \#nyamandisosmed 
Gambar 5. Langkah setting IG

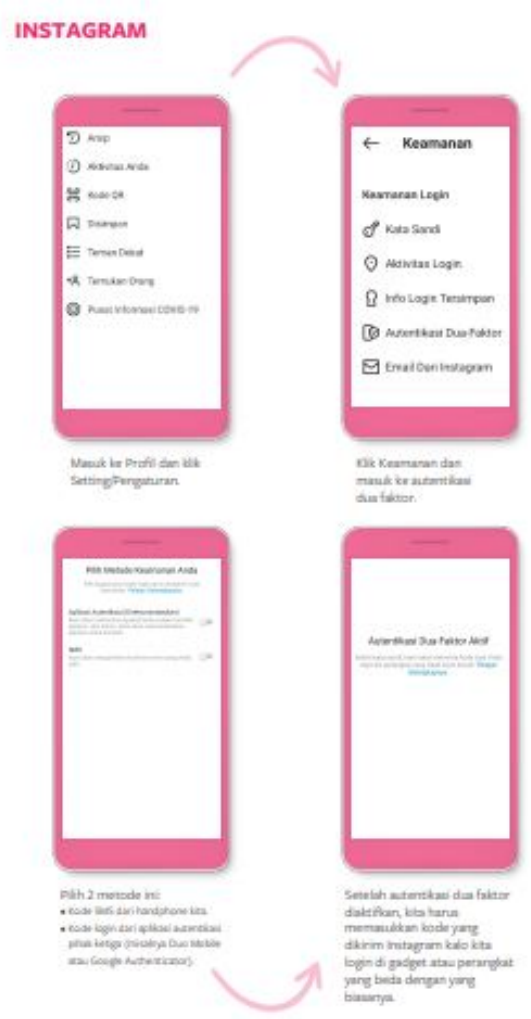

Sumber. \#nyamandisosmed

Gambar 6. settingWA

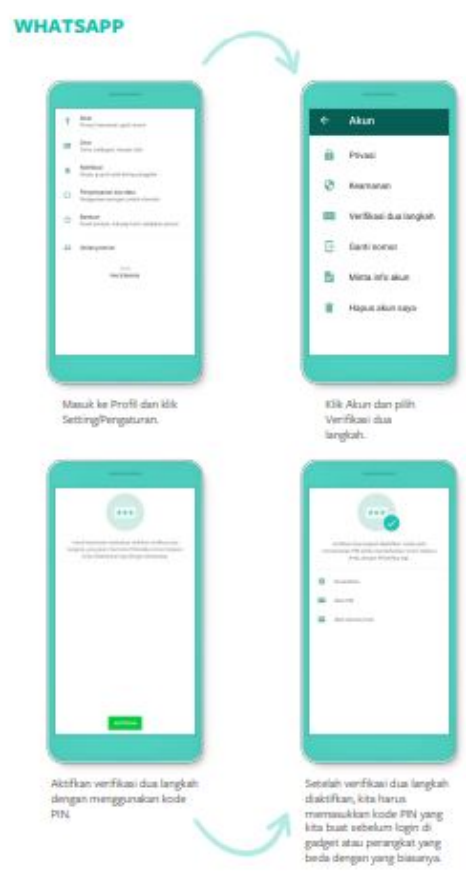

Sumber.\#nyamandisosmed 
6. Pemahaman Peserta Pelatihan

Gambar 7. Pemahaman setelah siswa melakukan pelatihan

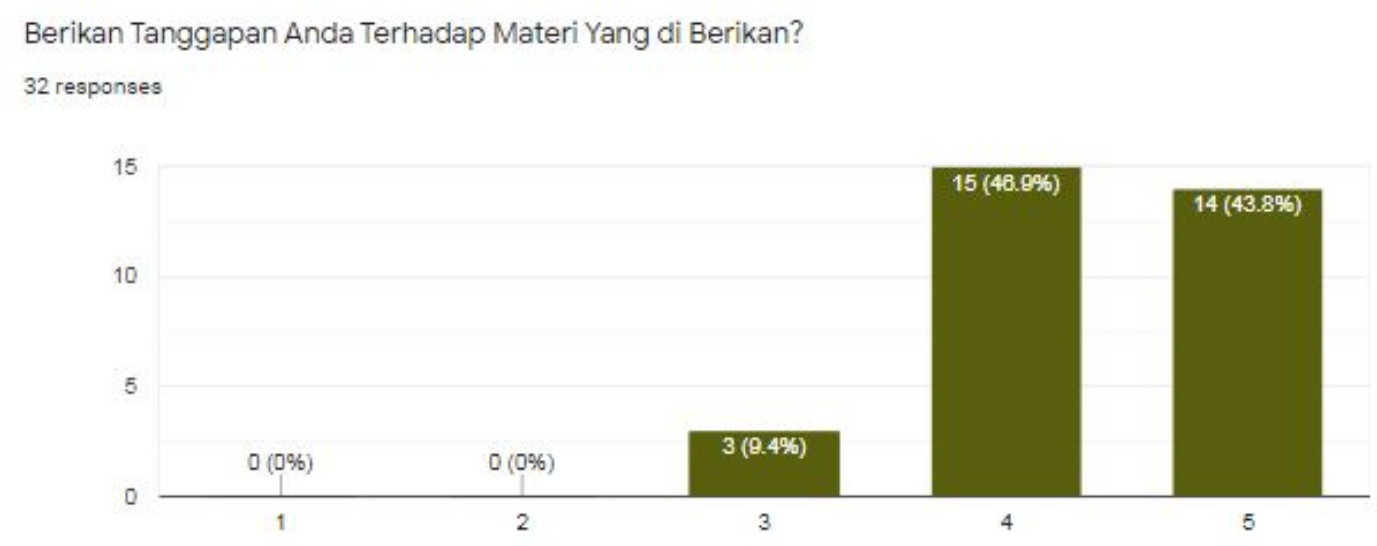

Dari banyaknya siswa yang menghadiri kegiatanini, 32 siswa telah mengisi kusioner yang telah disediakan tim Pengabdian. Dari hasil pengolahan data dalam kegiatan pelatihan 15 siswa (46.9\%) memahami materi yang diberikan, kemudian 14 (43,8)\% siswa cukup memahami dan sisa 3 siswa $(9,4 \%)$ netral. Dari feedbcak berupa note yang diberikan siswa, dapat disimpulkan peserta pelatihan merasa informasi yang diberikan penting untuk kenyamanan mereka mengakases sosial media. Mereka jadi memahami dan mengetahui data pribadi apa saja yang perlu di lindungi serta langkah preventif yang dapat mereka lakukan untuk melindungi data pribadi tersebut.

\section{SIMPULAN}

Berdasarkan pelatihan yang telah tim pengabdian lakukan, terdapat beberapa kesimpulan bahwa pelatihan dengan tema Literasi Media Digital dan Keamanan Data sangat diperlukan oleh siswa. Dilihat dari pelaksanaan pelatihan, beberapa siswa tidak cukup mengetahui data pribadi itu apa dan sebenarnya yang termasuk tidak boleh disebarkan di media sosial apa saja. Setelah menerima informasi mengenai data pribadi dan beberapa contoh kasus yang dipaparka pemateri tentang kejahatan pencurian data pribadi. Mereka dapat lebih memperhatikan setiap postingan di media sosial apakah ada kegiatan menyebarkan data pribadi.

Pelatihan serupa perlu sekali dilakukan, tentunya tidak hanya terbatas pada kalangan siswa SMA saja. Edukasi perlindungan data pribadi perlu terus dilakukan di kalangan masyarakat luas. Seperti para guru, orang tua hingga anak-anak, mengingat saat ini banyak anak kecil yang sudah menjadi pengguna gawai elektronik. 


\section{DAFTAR PUSTAKA}

Alyusi, S. D. (2016). Media Sosial: Interaksi, Identifikasi, dan Modal Sosial. Jakarta: Kencana.

Erikson, E., \& Cremers, A. (1989). Identitas dan siklus hidup manusia:(Bunga Rampai 1). PT Gramedia.

Littlejohn, S. W. (1999). Theories of Human Communication. California.

Nasrullah, R. (2014). Teori dan Riset Media Siber. Jakarta : Kencana.

Panduan anti ribet. Diunduh dair : https://indonesia.fb.com/wpcontent/uploads/sites/68/2021/06/Panduan-Anti-Ribet-Facebook.pdf

Ruben, B. D., \& Stewart, L. P. (2013). Komunikasi dan perilaku manusia. Jakarta: Rajawali Pers.

Setiawati, T., \& Agustini, V. D. (2021). IDENTITAS MAHASISWA UHAMKA DALAM MEDIA PEMBELAJARAN DARING. KOMUNIKATA57, 2(2), 52-57.

Hongo, S., Azranur, F., Rejito, J., Kom, M., Hadi, S., Suryana, I., \& Setiawan, A. Penanggung Jawab: M. Nur Anbiya Pimpinan Redaksi: Reynaldi Noer Rizki Anggota Penyunting: M. Fahmi Irfananda Syifa Fauziyah N. I. In Prosiding Seminar Teknik Inforrmatika Unpad. ISSN (Vol. 2615, p. 8434).

Chicago Wood, S. (2005). Online Communication, Linking Technology, Identity \& Culture. New Jersey : Lawrence Erlbaum Associates, Inc. Publishers 